\title{
Pattern of utilization of blood and blood components in obstetrics at tertiary care hospital
}

\author{
Vidyadhar B. Bangal*, Satyajit P. Gavhane, Kunal H. Aher, Dhruval K. Bhavsar, \\ Priyanka R. Verma, Swati D. Gagare
}

Department of Obstetrics and Gynecology, Rural Medical College, Pravara Institute of Medical Sciences, Loni, Maharashtra, India

Received: 11 August 2017

Accepted: 09 September 2017

\section{*Correspondence:}

Dr. Vidyadhar B. Bangal,

E-mail: vbb217@rediffmail.com

Copyright: () the author(s), publisher and licensee Medip Academy. This is an open-access article distributed under the terms of the Creative Commons Attribution Non-Commercial License, which permits unrestricted non-commercial use, distribution, and reproduction in any medium, provided the original work is properly cited.

\begin{abstract}
Background: Obstetric emergencies occur suddenly and unexpectedly. Blood transfusion becomes one of the live saving measures in such situations. Severe anaemia due to nutritional deficiency, obstetric haemorrhage either during pregnancy, labour or in postpartum period are the commonest indications for blood transfusion worldwide. Blood bank services play important role in saving lives in obstetric emergencies. Health institutions must carry out internal blood transfusion audits to reassure optimal and judicious use of blood and blood components.

Methods: Analysis of 755 Obstetric patients requiring blood transfusion in eighteen months period was done to find out the incidence and indications for blood transfusion at tertiary care hospital.

Results: Overall, 5.33\% of obstetric admissions required transfusion of blood or its components. Severe anaemia $(36.55 \%)$, accidental haemorrhage $(20.92 \%)$, postpartum haemorrhage $(8.34 \%)$, placenta praevia $(5.03 \%)$ and caesarean section $(10.33 \%)$ were the common indications for blood transfusion. In more than $65 \%$ cases, two or three unit of blood were transfused. In majority of cases (96\%) components were used.

Conclusions: Blood transfusion helped to save many lives in the present study. Severe anaemia and obstetric haemorrhage of varied aetiology were the common indications for blood transfusion. Component therapy helped to correct specific deficiency. Voluntary blood donation should be encouraged in the younger generation to keep adequate stock of blood in blood bank for emergency use. Preventive measures like improving dietary iron intake and prophylactic iron therapy will go a long way in reducing the need for blood transfusion in Obstetrics.
\end{abstract}

Keywords: Blood transfusion, Caesarean section, Fresh frozen plasma, Maternal mortality, Platelet transfusion, Postpartum haemorrhage

\section{INTRODUCTION}

In the world, pregnancy related haemorrhage is the most common cause of maternal death, causing $24 \%$ of, or an estimated 127,000 , maternal deaths annually. ${ }^{1}$ It has also been reported that massive $(2,000 \mathrm{ml}$ or more) and lifethreatening obstetric haemorrhage occurs in $3-5 \%$ and $0.1 \%$ of deliveries, respectively, and blood product transfusion is required in $0.3-1 \% .^{2,3}$ Obstetric haemorrhage remains a major cause of maternal mortality in India and is now the topmost leading cause of direct maternal deaths, accounting for approximately $20-30 \%$ of direct deaths. ${ }^{4}$

In the terminal stage of pregnancy, where the coagulation system is enhanced and the fibrinolytic system is suppressed, massive haemorrhage leads to consumption of coagulation factors, leading to further haemorrhage, forming a vicious circle such as disseminated intravascular coagulation (DIC). ${ }^{5-7}$ Correct understanding 
regarding the volume of blood loss is essential to determine whether transfusion should be performed. ${ }^{8-10}$ High-level capacity of pregnant women to tolerate obstetric hemorrhage masks changes in their vital signs, resulting in a delay in the detection and treatment of hypovolemia, which leads to further haemorrhage and shock. ${ }^{11,12}$ The comprehensive assessment of not only blood loss but also the cause of haemorrhage, a patient's medical condition, age, vital signs, and blood biochemical data is required to determine whether transfusion is necessary. ${ }^{13}$

Common emergency indications for blood transfusion are haemorrhage due to abortions, ruptured ectopic pregnancies, ante-partum haemorrhage and third stage complications like postpartum haemorrhage, retained placenta or acute inversion of uterus. Some patients of severe anaemia nearing term, liver or chronic kidney diseases on dialysis, haemophilia require blood transfusion. Excess blood loss during obstetric surgeries like dilatation and evacuation for incomplete or inevitable abortions, suction evacuation for vesicular mole and excess bleeding during caesarean section, placenta accreta and rupture of uterus also need emergency blood transfusions. The obstetrician and anaesthesiologists are mainly involved in the decision about need for blood transfusion.

The present study aimed to find out the incidence and indications of transfusion of blood and blood components in Obstetrics at tertiary care hospital.

\section{METHODS}

Retrospective cross sectional study was carried out at Pravara Rural Hospital. Data related to blood transfusion for Obstetric patients for one and half year duration, from January 2016-June 2017 was collected and analysed. Data regarding number of blood units transfused and the indications for the transfusion was collected from all maternity wards, operation theatre, labour room and blood of Pravara Rural Hospital, Loni.

Pravara Rural Hospital is a multi-speciality 1275 bedded tertiary care teaching hospital, situated in rural area of Ahmednagar District in Maharashtra. India. The hospital is providing maternal health care and services since last 40 years and has good reputation in the area. Majority of high risk and complicated obstetric cases are referred to this hospital for specialist management. Hospital provides 24 hours maternity and neonatal care services. It has a well-equipped operation theatre and intensive care facilities and state of art neonatal care unit facilities. Approximately 8500 deliveries take place in the hospital per year.

The hospital has well equipped blood bank facility which functions 24 hours a day. The blood bank provides all components of blood as per the stock position and demand. Hospital conducts blood donation camps on regular basis to maintain the adequate stock position in the blood bank. The hospital being located near state highway and close to international pilgrimage centre, there are many road traffic accident cases admitted on regular basis, needing urgent blood transfusions. Relevant data of one year and six months was collected, compiled, analysed and interpreted as per study objectives. Data was analysed using SPSS version 21.

\section{RESULTS}

The retrospective analysis of blood utilization was carried out at Pravara rural hospital over a period of 18 months. During the study period, there were 14,156 Obstetric admissions. Total number of deliveries during study period was 12,603 , including 3561 caesarean sections. There were 481 abortions including medical termination of pregnancies (MTP). Total 755 patients (5.33\%) required blood and component transfusion (Table 1).

Table 1: General information about hospital admissions, deliveries and obstetric operations during study period.

\begin{tabular}{|l|l|}
\hline General Information & Number \\
\hline No. of Obstetric admissions & 14,156 \\
\hline No. of Deliveries (Total) & 12,603 \\
\hline No of Caesarean sections & 3561 \\
\hline No. of Medical termination of pregnancy & 225 \\
\hline No. of Spontaneous abortions & 256 \\
\hline $\begin{array}{l}\text { No. of Patients requiring blood transfusion } \\
\text { Percentage of Obstetric admissions } \\
\text { requiring blood transfusion }\end{array}$ & 755 \\
\hline
\end{tabular}

During study period, 8122 blood units were issued from the hospital blood bank to all departments, of which 2235 blood units were issued to Obstetric patients. Total of $27.51 \%$ of blood was issued to Obstetrics, that includes $10.71 \%$ of whole blood and $29.10 \%$ of blood components. Out of total blood units issued to Obstetrics, $96.64 \%$ were components and only $3.35 \%$ were whole blood units (Table 2).

Table 2: Showing obstetric blood and blood component requirement.

\begin{tabular}{|llll|}
\hline Department & $\begin{array}{l}\text { Total no. } \\
\text { of blood } \\
\text { units } \\
\text { issued }\end{array}$ & $\begin{array}{l}\text { Total no. } \\
\text { of whole } \\
\text { blood } \\
\text { issued }\end{array}$ & $\begin{array}{l}\text { Total no of } \\
\text { components issued } \\
\text { (packed cell, fip, } \\
\text { platelets) }\end{array}$ \\
\hline $\begin{array}{l}\text { All } \\
\text { departments }\end{array}$ & 8122 & 700 & 7422 \\
\hline Obstetrics & 2235 & 75 & 2160 \\
\hline $\begin{array}{l}\text { \% of blood } \\
\text { units issued } \\
\text { to obstetrics }\end{array}$ & 27.51 & 10.71 & 29.10 \\
\hline
\end{tabular}

It was observed that $46.62 \%$ patients were transfused with fresh frozen plasma, $45.81 \%$ patients were transfused with packed cell volume transfusion, $4.02 \%$ patents were transfused with platelet transfusion. Very small percentage of patients were transfused with whole blood 
$(0.33 \%)$ and cryoprecipitate transfusion $(0.33 \%)$ (Table 3).

Table 3: Showing utilization of blood and blood components in obstetrics.

\begin{tabular}{|lll|}
\hline $\begin{array}{l}\text { Type of blood and } \\
\text { components }\end{array}$ & $\begin{array}{l}\text { No of units } \\
\text { transfused }(\mathbf{n}=2235)\end{array}$ & $\%$ \\
\hline Whole blood & 75 & 0.33 \\
\hline Packed cell volume & 1024 & 45.81 \\
\hline Fresh frozen plasma & 1042 & 46.62 \\
\hline Platelets & 90 & 4.02 \\
\hline Cryoprecipitate & 04 & 0.17 \\
\hline
\end{tabular}

In the present study, it was observed that severe anaemia either during pregnancy or during postpartum period was most common indication $(36.55 \%)$ for blood transfusion.

Accidental haemorrhage (20.92\%), caesarean section (10.33\%), postpartum haemorrhage $(8.34 \%)$, placenta praevia $(5.3 \%)$ and ruptured ectopic pregnancy $(5.03 \%)$ were other common indications requiring blood transfusion. Less common indications were abortions, complications of third stage of labour, vesicular mole evacuation etc (Table 4).

Table 4: Showing indications for transfusions of blood and blood components.

\begin{tabular}{|ll|}
\hline Indication & $\begin{array}{l}\text { Number of } \\
\text { cases }(\%)\end{array}$ \\
\hline Postpartum haemorrhage & $63(8.34)$ \\
\hline Accidental haemorrhage & $158(20.92)$ \\
\hline Placenta praevia & $38(5.03)$ \\
\hline Abortions & $22(2.91)$ \\
\hline Ectopic pregnancies & $38(5.03)$ \\
\hline Vesicular mole & $17(2.25)$ \\
\hline Rupture uterus & $04(0.52)$ \\
\hline Caesarean section & $78(10.33)$ \\
\hline Obstetric hysterectomy & $06(0.79)$ \\
\hline Retained placenta/Inversion of uterus & $15(1.98)$ \\
\hline $\begin{array}{l}\text { Severe anaemia during } \\
\text { pregnancy/postpartum anaemia }\end{array}$ & $276(36.55)$ \\
\hline Acute or chronic liver and kidney diseases & $13(1.72)$ \\
\hline Haemoglobinopathies & $05(0.66)$ \\
\hline Others & $22(2.91)$ \\
\hline
\end{tabular}

able 5: Distribution of cases as per blood unit requirement.

\begin{tabular}{|lll|}
\hline $\begin{array}{l}\text { No. of blood units } \\
\text { transfused per case }\end{array}$ & $\begin{array}{l}\text { Total no. of } \\
\text { cases }(\mathbf{N}-755)\end{array}$ & $\%$ \\
\hline 1 & 104 & 13.77 \\
\hline 2 & 285 & 37.74 \\
\hline 3 & 196 & 25.96 \\
\hline 4 & 75 & 9.93 \\
\hline 5 and More & 95 & 12.58 \\
\hline
\end{tabular}

It was observed that $63 \%$ patients either required 2 or 3 units of blood transfusion. Only $13.77 \%$ patients required blood transfusion. Five or more units of blood transfusion was required in $12.58 \%$ patients (Table 5)

\section{DISCUSSION}

Pregnancy although a physiological state, can turn pathological, suddenly and unexpectedly, if not cared for. Acute blood loss can occur in first half of pregnancy due to complications like abortions, ectopic pregnancy rupture and vesicular mole. In later half of pregnancy, there can be haemorrhage due to low lying placenta or accidental haemorrhage. During labour, women may develop third stage haemorrhage or other complications resulting in severe blood loss and sudden deterioration in general condition of mother. Immediate and and rapid replacement of sufficient and safe blood becomes essential to save the lives. No other fluid can replace the blood and thus the importance of blood bank in Obstetrics. No maternity hospital is safe for confinement unless supported by blood bank facility.

Blood transfusion is one of the life saving measures in Obstetrics. It may be required on emergency basis in obstetric haemorrhage or for correction of severe anaemia. Government approved blood banks provide blood or blood components as per the patients needs. The utilization of blood in maternity hospital mainly depends on the number of deliveries and number of high risk cases admitted. Many a times, there is shortage of blood in the blood banks, as the blood collection (Donation) is much less than the blood requirement. Advanced blood bank technology and availability of blood components help in optimal utilization of scarce blood resources. Blood transfusion does carry risk of transmission of infections and anaphylactic reactions. Various academic bodies have put forth the guidelines for rational use of blood in Obstetrics. Health professionals must understand the importance of judicious use of blood.

Chowdhury et al in their study titled evaluation of blood transfusion practices in Obstetrics and Gynaecology in a tertiary hospital in Bangladesh reported that Transfusion rate in total admitted patients was 9.23\%. ${ }^{14}$ Most common indication for blood transfusion in obstetric patients was mild preoperative anaemia with or without excessive bleeding during cesarean section $(63.92 \%)$ and second common cause was antenatal anaemia $(24.05 \%)$. In gynecological cases abortion (45.91\%) was the commonest indication for blood transfusion and next common conditions were total abdominal hysterectomy (20.40\%), vaginal hysterectomy (7.14\%), ectopic pregnancy and post coital tear $(6.12 \%)$ and $(6.12 \%)$.

Nigam et al in their study titled blood transfusion in obstetrics reported that transfusion of blood and blood components is a common practice in obstetric wards but it is not without risk. ${ }^{15}$ The incidence of transfusion reactions varies from 4 in every hundred transfusions for 
non-haemolytic reactions to one in every 40,000 for haemolytic transfusion reactions. The physiological basis of blood transfusion is outlined in this article. Most of the donated blood is processed into components: packed red cells (PRBCs), platelets, and fresh frozen plasma (FFP) or cryoprecipitate. Various alternatives to blood transfusion exist and include auto transfusion, preautologous blood storage, use of oxygen carrying blood substitutes and intraoperative cell salvage. Despite the risks associated with transfusions, obstetricians are frequently too aggressive in transfusing blood and blood products to their patients. Acute blood loss in obstetrics is usually due to placenta praevia, postpartum blood loss and surgery related. An early involvement of a consultant obstetrician, anaesthetist, haematologist and the blood bank is essential. There are no established criteria for initiating red cell transfusions and the decision is purely based on clinical and haematological parameters, which have been discussed along with the general principles of blood transfusion in obstetrics and some practical guidelines.

Adukauskiene et al in their published a paper "The usage of blood components in obstetrics", reported that major obstetric hemorrhage remains the leading cause of maternal morbidity and mortality worldwide. ${ }^{16}$ Even though blood transfusion may be a life-saving procedure, an inappropriate usage of blood products in obstetric emergencies especially in cases of massive bleeding is associated with increased morbidity and risk of death. There is evidence of very significant variation in the use of blood products (red cells, platelets, fresh frozen plasma, or cryoprecipitate) among clinicians in various medical institutions, and sometimes indications for transfusion are not correctly motivated. The transfusion of each single blood product must be performed only in case of evaluation of expected effect. The need for blood products and for their combination is necessary to estimate for each patient individually in case of obstetric emergencies either. Indications for transfusion of blood components in obstetrics are presented in order to improve the skills of doctors and to optimize therapeutic options in obstetric emergencies.

Jadon and Bagai in their study titled "Blood transfusion practices in obstetric anaesthesia", reported that the blood transfusion is an essential component of emergency obstetric care and appropriate blood transfusion significantly reduces maternal mortality. ${ }^{17}$ Obstetric haemorrhage, especially postpartum haemorrhage, remains one of the major causes of massive haemorrhage and a prime cause of maternal mortality. Blood loss and assessment of its correct requirement are difficult in pregnancy due to physiological changes and co-morbid conditions. Many guidelines have been used to assess the requirement and transfusion of blood and its components. Infrastructural, economic, social and religious constraints in blood banking and donation are key issues to formulate practice guidelines. Available current guidelines for transfusion are mostly from the developed world; however, they can be used by developing countries keeping available resources in perspective.

Schorn and Phillippi published an article titled "Volume Replacement Following Severe Postpartum Hemorrhage" suggested that for postpartum volume replacement, crystalloid fluids should be used only until the amount of blood loss becomes severe. ${ }^{18}$ Once a woman displays signs of hypovolemia, blood products including packed red blood cells, fresh frozen plasma, platelets, and recombinant factor VIIa should be used for volume replacement. Overuse of crystalloid fluids increases the risk for acute coagulopathy and third spacing of fluids. A massive transfusion protocol is one mechanism to provide a rapid, consistent, and evidence-based team response to this life-threatening condition.

Anjali et al reported in study of retrospective analysis of ninety cases, the indications of blood transfusion, use of whole blood and blood components and measures taken to minimize the need of blood transfusion. The indications in obstetric cases were evenly distributed between three - anaemia complicating pregnancy, obstetric haemorrhage and postpartum correction of anaemia. The finding of this study co relate well with the present study. ${ }^{19}$ Special measures to minimize BT requirement were practiced in $41.4 \%$ of obstetric cases and $25 \%$ of gynaecology cases. They reported a need to change the inappropriate blood transfusion practices such as use of blood transfusion for preoperative correction of anaemia in elective surgery, use of whole blood for correction of anaemia. Use of alternative measures to reduce the need of blood transfusion should be practiced more aggressively.

Fresh frozen plasma is very useful in the management of accidental haemorrhage and cases with massive blood loss. It prevents or controls dreadful complication like disseminated intravascular coagulation. Severe variety of abruption may demand multiple units of fresh frozen plasma. Aggressive obstetric management is the key to success. It also helps in preventing other complications like acute renal failure and hypovolemic shock.

Single unit blood transfusion, literally has no meaning in Obstetrics and thus should be avoided. Similarly, whole blood transfusion should be avoided as much as possible. Decision of blood transfusion, its time, type, quantity are usually decided by the treating Obstetrician. Timely consultation or second opinion from anaesthesiologist, intensivist or physician help in correct decision making regarding type and amount of blood to be replaced. Situations requiring massive blood transfusion are not rare in India. Rupture uterus, traumaticpostpartum haemorrhage, severe variety of concealed accidental haemorrhage, disseminated intravascular coagulation are some of them. These cases require more supervision and monitoring regarding their haemodynamic instability. Invasive monitoring, ionotropic support, invasive 
ventilation are often accompaniments of massive blood transfusion.

Blood banks must be informed in advance, if Obstetrician suspects the possible need of massive blood transfusion. Networking of blood banks helps in making blood available in short period of time. Every institution must keep the information about neighbouring blood banks and their blood stock position on daily basis. The relatives of the patients should be encouraged to donate blood.

In India, the number of blood banks is meagre as compared to the developed countries. The blood banks are not within close reach of the hospitals which are catering the maternity services. The problems are severe in rural and are even worst in tribal areas. The blood stock is often insufficient and does not assure the availability of blood all dire emergencies. Government has not taken sufficient efforts to establish the adequate number of blood banks as per the population requirements. Obstetrician has to anticipate the possible need for blood transfusion during case management. Failure to anticipate can result into disaster.

As it is rightly said, prevention is better than cure, thus during nine months period, Obstetrician must encourage pregnant women to maintain their haemoglobin level in normal range. Dietary advice regarding consumption of iron rich substances and prophylactic iron therapy, help in maintaining normal haemoglobin level. Moderate anaemia may be treated with intravenous iron therapy in third trimester, so that haemoglobin rise takes place over few weeks' time. Blood transfusion should be spared for severe anaemia with cardio respiratory symptoms. Packed cell volume should be preferred over whole blood to avoid volume overload.

\section{CONCLUSION}

Blood transfusion is a life saving measure in Obstetrics. Common indications for blood transfusion are severe degree of anaemia, either due to nutritional deficiency or acute or chronic blood loss. Judicious and optimum use of blood is recommended in such situations. Blood transfusion audit is useful in maintaining the quality of health care services. Voluntary blood donation programmes needs to be strengthened. Government should establish more blood banks and network them for improving their effectiveness. Component therapy should be encouraged and whole blood transfusion be preferably discouraged in resource constraint settings.

\section{ACKNOWLEDGMENTS}

We acknowledge the Centre for Social Medicine and Pravara Institute of Medical Sciences (Deemed university) for the support in publication of this study.

Funding: No funding sources

Conflict of interest: None declared
Ethical approval: The study was approved by the Institutional Ethics Committee

\section{REFERENCES}

1. Prevention of Postpartum Hemorrhage Initiative, 2011, Available at http://www.pphprevention.org/pph.php.

2. Balki M, Dhumne S, Kasodekar S, Seaward G, Carvalho JC. Blood transfusion for primary postpartum hemorrhage: a tertiary care hospital review. J Obstet Gynecol Canada. 2008;30(11):10027.

3. Drife J. Management of primary postpartum haemorrhage. Br J Obstet Gynecol. 1997;104(3):2757.

4. James AH, Paglia MJ, Gernsheimer T, Grotegut C, Thames B. Blood component therapy in postpartum hemorrhage. Transfusion. 2009;49(11):2430-3.

5. Bremme KA. Haemostatic changes in pregnancy. Best Pract Res Clin Haematol. 2003;16:153-68.

6. Brenner B. Haemostatic changes in pregnancy. Thrombosis Res. 2004;114(5-6):409-414.

7. Santoso JT, Saunders BA, Grosshart K. Massive blood loss and transfusion in obstetrics and gynecology. Obstetr Gynecologic Surv. 2005;60(12)827-37.

8. Bose P, Regan F, Paterson-Brown S. Improving the accuracy of estimated blood loss at obstetric haemorrhage using clinical reconstructions. $\mathrm{Br} \mathrm{J}$ Obstet Gynecol. 2006;113(8):919-24.

9. Dildy GA, Paine AR, George NC, Velasco C. Estimating blood loss: can teaching significantly improve visual estimation? Obstet Gynecol. 2004;104(3):601-6.

10. Duthie SJ, Ven D, Yung GLK, Guang DZ, Chan SYW, Ma HK. Discrepancy between laboratory determination and visual estimation of blood loss during normal delivery. Eur J Obstet Gynecol Reprod Biol. 1991;38(2):119-24.

11. Bonnar J. Acquired bleeding disorders: bleeding in obstetrics and surgery. The Southeast Asian J Trop Med Public Health. 1993;24:10-2.

12. Hofmeyr GJ, Mohlala BKF. Hypovolaemic shock. Best Practice Res Clin Obstet Gynecol. 2001;15:64562.

13. Nuttall GA, Stehling LC, Beighley CM, Faust RJ, Current transfusion practices of members of the American society of anesthesiologists: a survey. Anesthesiology. 2003;99(6):1433-43.

14. Chowdhury F, Akhter S, Islam A, Rayen J, Begum $\mathrm{N}$, Begum F. Evaluation of blood transfusion practices in obstetrics and gynecology in a tertiary hospital in Bangladesh. J Bangladesh College Physicians Surgeons. 2016;34:9-14.

15. Nigam A, Prakash A, Saxena P. Blood transfusion in Obstetrics. Kathmandu Univ Med J. 2013;11(44):355-9.

16. Adukauskienè D, Veikutienè A, Adukauskaitė A, Veikutis V, Rimaitis K. The usage of blood 
components in obstetrics. Medicina. 2010;46(8):5617

17. Jadon A, Bagai R. Blood transfusion practices in obstetric Anaesthesia. Indian J Anaesth. 2014;58(5):629-36.

18. Schorn MN, Phillippi JC. Volume Replacement Following Severe Postpartum Hemorrhage. J Midwifery Women's health. 2014;59(3):336-43.

19. Kawthalkar A, Kose V, Joshi S, Bhalerao A, Kumare B, Somalwar S. Blood transfusion in Obstetrics and
Gynaecology: A retrospective analysis. Panacea J Med Sci. 2015;5(3):109-12.

Cite this article as: Bangal VB, Gavhane SP, Aher KH, Bhavsar DK, Verma PR, Gagare SD. Pattern of utilization of blood and blood components in obstetrics at tertiary care hospital. Int J Reprod Contracept Obstet Gynecol 2017;6:4671-6. 